\title{
STUDI KUALITATIF TENTANG AKTIFITAS (OLAH RAGA) \\ PADA PENDERITA DIABETES MELLITUS TYPE II DI PUSKESMAS PERIUK JAYA KOTA TANGERANG
}

\author{
*Wasludin
}

\begin{abstract}
Abstrak
Berdasarkan informasi dari pihak puskesmas Periuk Jaya, dari 49 orang penderita DM yang berobat ke Puskesmas Periuk Jaya, kurang dari $45 \%$ dari penderita yang melakukan olahraga sesuai dengan anjuran kesehatan dalam rangka membantu mengontrol kadar gula darah padahal mereka sudah mendapat penjelasan tentang aktifitas (olah raga) yang baik bagi penderita diabetes melitus. Beberapa orang dari mereka mengaku alasan tidak melakukan olah raga tersebut karena tidak memahami, kesibukan, dan beberapa alasan lain yang belum diketahui, (Dinkes Kota Tangerang, 2014)

Penelitian ini menggunakan desain penelitian kualitatif dengan menggunakan teknik pengumpulan data melalui fokus group diskusi (FGD) pada populasi (informan) yaitu penderita diabates mellitus type II yang berobat ke Puskesmas Periuk Jaya Kota Tangerang sebanyak tujuh (tujuh) orang. Analisis dilakukan dengan merangkum pendapat responden tentang aktifitas (olah raga) yang tepat dan benar bagi penderita diabetes melitus type II.

Berdasarkan hasil diskusi dengan informan, terdapat 3 orang informan yang sudah melakukan olahraga berupa pus up, site up, jalan-jalan, lari-lari kecil selama 30 menit 40 menit yang dilakukan sebanyak 4 - 5 kali dalam satu minggu dan bahwa mereka belum mengetahui cara mengukur tepat/tidaknya atau bilamana menghentikan olahraga yang mereka lakukan, mereka menghentikan olahraga apabila sudah capek/lelah, berkeringat, atau sudah mencapai 30 - 40 menit saja.
\end{abstract}

Kata kunci : Tangerang, olahraga, diabetes melitus

*Poltekkes Kemenkes Banten 
QUALITATIVE STUDY ABOUT ACTIVITY (Sport) In PEOPLE With TYPE II DIABETES MELLITUS In CLINICS And The PERIUK JAYA TANGERANG

\author{
Wasludin
}

\begin{abstract}
Based on information from the clinics and the Periuk Jaya, out of 49 people who sought to DM sufferers seek medical Pot, less than 45\% of sufferers who do sports in accordance with the advice of health in order to help control blood sugar levels and they have got a description of the activities (sport) is good for sufferers of diabetes mellitus. Some of them confessed the reason doesn't do the sport because it does not understand, busyness, and some other reasons that are not yet known, (the city of Tangerang Health Office, 2014)

This qualitative study using a research design using data collection techniques through focus group discussion (FGD) on population (the informant) namely type II diabetics mellitus sufferer whose medical treatment to the Clinic and the Periuk Jaya Tangerang city seven (seven) people. The analysis is performed with the activities summarize the opinions of respondents (sport) the right and true for patients with type II diabetes mellitus.

Based on the results of the discussion with the informant, there are three people who have been sports informer conduct be Kitty up, site up, streets, running for 30 minutes-40 minutes the performed as many as 4-5 times a week and those that do not know how to measure right/not when or they stop doing sports, sports when they've stopped the tired/exhausted, sweating, or had already reached 30-40 minutes.
\end{abstract}

Keywords: Tangerang, exercise, diabetes mellitus 


\section{Pendahuluan}

Jumlah penderita diabetes mellitus didunia dari tahun ke tahun mengalami peningkatan, hal ini berkaitan dengan jumlah populasi yang meningkat, life expectancy bertambah, urbanisasi yang merupakan pola hidup tradisional ke pola hidup modern, prevalensi obesitas meningkat dan aktifitas fisik kurang. Diabetes mellitus perlu diamati karena sifat penyakit yang kronik progesif, jumlah penderita semakin meningkat dan banyak dampak negatif yang ditimbulkan (Depkes RI, 2010).

Di Indonesia berdasarkan penelitian epidemologi didapatkan prevalansi diabetes mellitus sebesar 1,5-2,3\%. Pada penduduk yang usia lebih dari 15 tahun, bahkan di daerah urban prevalensi DM sebesar $14,7 \%$ dan di daerah rural sebesar $7,2 \%$. Prevalensi tersebut meningkat $2-3$ kali dibandingkan dengan negara maju, sehingga diabetes mellitus merupakan masalah kesehatan masyarakat yang serius, dan dapat terjadi pada lansia (Depkes RI 2010).

Sedangkan data yang penulis dapatkan dari Puskesmas Periuk Jaya Kota Tangerang pada tahun 2013 terdapat 45 orang dan terjadi peningkatan tahun 2014 pada bulan Januari sampai bulan Nopember yaitu 49 orang yang berobat jalan di Puskesmas Periuk Jaya. Untuk menjaga kadar gula darah mendekati normal, diperlukan upaya oleh penderita yaitu diet, minum obat diabet secara tepat dan olah raga yang tepat dan teratur. Program puskesmas untuk mengatasi Diabetes Mellitus yaitu dengan melakukan penjaringan di Posbindu satu bulan sekali dan melakukan penyuluhan pada pasien Diabetes Melitus, untuk melakukan pola hidup sehat dengan diet yang tepat yaitu mengkomsumsi makanan sehat, rutin kontrol untuk mendapatkan obat dan berolahraga agar gula darah tetap stabil dan berada mendekati batas normal, (Dinkes Kota Tangerang 2014).

Penelitian ini menggunakan desain penelitian kualitatif dengan menggunakan teknik pengumpulan data melalui fokus group diskusi (FGD) pada populasi (informan) yaitu penderita diabates mellitus type II yang berobat ke Puskesmas Periuk Jaya Kota Tangerang sebanyak 7 (tujuh) orang. Analisis dilakukan dengan merangkum pendapat responden tentang pengetahuan mengenai DM dan aktifitas (olah raga) yang tepat dan benar bagi penderita diabetes melitus type II.

\section{Metoda Penelitian}

Berdasarkan tujuan penelitian diatas, maka desain penelitian yang digunakan adalah penelitian kualitatif dengan metode 
pengumpulan data melalui fokus group diskusi (FGD) dengan menggunakan instrumen berupa pedoman wawancara yang susun penelitian meliputi pertanyaan untuk menggali pengetahuan tentang penyakit diabetes melitus, pengetahuan tentang olahraga dan pelaksanaan olahraga pada penderita diabetes melitus.

Karakteristik Sampel dalam penelitian ini adalah responden yang menderita diabetes mellitus type II baik penderita lama maupun baru yang berobat di Puskesmas Periuk Jaya pada bulan Juni 2015. Sedangkan untuk menentukan besar sampel, karena penelitian ini penelitian kualitatif dengan metode pengumpulan data melalui FGD, maka sampel yang diperlukan sebanyak 7 orang yang kebetulan berobat pada waktu peneliti mengumpulkan data dan bersedia menjadi informan/sumber data.

Analisa data yang digunakan dalam penelitian ini adalah mencantumkan semua jawaban atau informasi dari informan yang tulis berdasarkan susunan pedoman wawancara yang dipakai sebagai patokan oleh peneliti.

\section{Hasil}

\section{Pengetahuan pengertian DM}

Informan telah memahami tentang pengertian diabetes melitus (DM) walaupun dinyatakan dengan menggunakan istilah yang berbeda sesuai dengan informasi/pengetahuan yang mereka miliki, seperti pernyataan berikut, "menurut informan (1), DM adalah penyakit gula dan menahun atau air seni mengandung gula, sedangkan menurut informan (3), DM adalah penyakit kencing manis kering atau basah, dan Tn.FH menyatakan bahwa DM adalah penyakit kencing manis akibat banyak makan gula atau keturunan".

\section{Pengetahuan pencegahan DM}

Informan telah memahami upaya untuk mencegah terjadinya DM dilakukan dengan tidak makan berlebihan dan tidak minum minuman yang mengandung gula pasir, seperti pernyataan berikut, "menurut informan (1) dan (2), pencegahan agar tidak terkena DM yaitu dengan pola hidup baik yaitu dengan cara tidak makan nasi berlebihan, tidak minum minuman yang mengandung gula, dan olah raga, demikian juga pendapat (3) dan (5) yang menyatakan bahwa untuk mencegah DM yaitu jangan makan berlebihan".

\section{Pengetahuan mempertahankan kadar gula}

Informan telah memahami cara mempertahankan kadar gula darah pada penderita DM dengan cara diet, olah raga, dan minum obat sesuai dengan aturan dokter seperti pernyataan berikut, “informan (2), saya sekali makan nasi hanyak $7-8$ suap dan minum obat yang benar, dan olahraga, sedangkan (1), (7) dan (5) serta (3) menyatakan dengan makan 
sedikit (7 suap), minum obat tidak boleh telat setiap kali mau makan.

\section{Pengetahuan jenis olahraga DM}

Informan ada yang sudah mengetahui dan melakukan olahraga yang tepat bagi penderita DM, tetapi masih ada informan yang tidak mengetahui dan tidak melakukan olahraga karena tidak tahu dan malas/lemes. "informan (1) menyatakan olahraga yang saya lakukan ialah pus up, site up, lari-lari kecil, sedangkan (2) dan (7) menyatakan bahwa olah raga yang saya lakukan yaitu jalan-jalan pagi, dan (3) menyatakan saya tidak pernah olahraga karena sudah capek nyuci dan ngepel tiap pagi, saya tidak pernah olahraga karena lemes. Selain itu, informan (4) dan (6) mengatakan tidak pernah olahraga karena saya tidak tahu”.

\section{Pengetahuan lama dan frekuensi olahraga}

Informan yang sudah melakukan olahraga antara 30 - 40 menit setiap kali melakukan olahraga, sedangkan informan lainnya tidak tahu karena tidak pernah melakukan olahraga yang khusus, seperti berikut, "informan (1), saya olahraga seperti lari-lari kecil selama kurang lebih 40 menit, sedangkan (2) dan (7) menyatakan cukup olahraga jalan-jalan selama kurang lebih 30 menit saja. Informan lainnya tidak melakukan olahraga sehingga mereka tidak tahu lama waktu olahraga yang tepat".

Menurut informan yang sudah melakukan olahraga, menyatakan bahwa mereka melakukan olahraga dalam satu minggu 4 - 5 kali, sedangkan informan lainnya tidak tahu karena tidak pernah melakukan olahraga khusus kecuali aktifitas sehari-hari.

\section{Pelaksanaan olahraga}

Berdasarkan hasil diskusi dengan 3 orang informan disimpulkan bahwa mereka sudah melakukan olahraga berupa pus up, site up, jalan-jalan, lari-lari kecil selama 30 menit - 40 menit yang dilakukan sebanyak 4 - 5 kali dalam satu minggu. Dari 3 informan yang sudah melakukan olahraga, diperoleh kesimpulan bahwa mereka belum mengetahui cara mengukur tepat/tidaknya atau bilamana menghentikan olahraga yang mereka lakukan, mereka menghentikan olahraga apabila sudah capek/lelah, berkeringat, atau sudah mencapai 30 - 40 menit saja.

\section{Pembahasan}

\section{Pengetahuan tentang Diabetes Melitus}

Berdasarkan hasil diskusi dengan informan tentang penyakit diabetes melitus, mereka telah mengetahui tentang DM karena mereka telah mengalami penyakit tersebut dan telah mendapat informasi melalui penyuluhan kesehatan pada waktu periksa dan berobat ke 
puskesmas. Sesuai dengan pendapat Hasdianah (2012:8), diabetes mellitus atau penyakit gula atau penyakit kencing manis adalah penyakit yang ditandai dengan kadar glukosa darah yang melebihi normal (hiperglikemia) akibat tubuh kekurangan insulin baik absolut maupun relative. Namun terdapat perbedaan istilah dalam menyebut atau menamakan penyakit DM misalnya istilah penyakit banyak gula, air seni mengandung gula, ada DM kering dan DM basah. Responden juga telah mengetahui penyebab DM walaupun dengan istilah berbeda seperti keturunan, pola atau kebiasaan makan nasi/gula tinggi, atau penyakit bawaan.

Semua informan sama pendapatnya tentang cara mempertahankan kadar gula darah mendekati normal yaitu dengan diet yaitu makan nasi tidak berlebihan (cukup 7 - 8 suap saja), minum obat yang tepat waktu dan tidak boleh putus. Demikian seperti dinyatakan informan (2), saya sekali makan nasi hanyak 7 - 8 suap dan minum obat yang benar, dan olahraga, sedangkan (1), (7) dan (5) serta (3) menyatakan dengan makan sedikit (7 suap), minum obat tidak boleh telat setiap kali mau makan.

Memperhatikan hal tersebut pada umumnya responden telah memahami tentang penyakit dan penyebabnya karena mereka telah mendapat informasi dari keluarga, tetangga, dan petugas kesehatan pada waktu mereka berobat. Hal ini sesuai dengan pendapat Notoatmodjo (2007) tentang cara memperoleh pengetahuan melalui pengalaman. Pengalaman adalah guru yang baik, demikian bunyi pepatah. Pepatah ini mengandung maksud bahwa pengalaman itu merupakan sumber pengetahuan, atau pengalaman itu merupakan suatu cara untuk memperoleh kebenaran pengetahuan. Oleh sebab itu pengalaman pribadi pun dapat digunakan sebagai upaya memperoleh pengetahuan.

\section{Pengetahuan tentang aktifitas/ olahraga}

Berdasarkan hasil diskusi, disimpulkan bahwa informan ada yang sudah mengetahui dan melakukan olahraga yang tepat bagi penderita DM, tetapi masih ada informan yang tidak mengetahui dan tidak melakukan olahraga karena tidak tahu dan malas/lemes. Sebagian informan sudah mengetahui dan sudah melakukan olahraga antara 30 - 40 menit setiap kali melakukan olahraga, sedangkan informan lainnya tidak tahu karena tidak pernah melakukan olahraga yang khusus. Berdasarkan hasil diskusi di atas dismpulkan bahwa informan yang sudah melakukan olahraga khusus DM dilaksanakan $4-5$ kali dalam satu minggu.

Memperhatikan hal tersebut pada umumnya responden telah memahami tentang penyakit dan penyebabnya karena mereka telah mendapat informasi dari keluarga, tetangga, dan petugas kesehatan 
pada waktu mereka berobat. Hal ini sesuai dengan pendapat Notoatmodjo (2007) tentang cara memperoleh pengetahuan melalui pengalaman dan coba-coba. Pengalaman adalah guru yang baik, demikian bunyi pepatah. Pepatah ini mengandung maksud bahwa pengalaman itu merupakan sumber pengetahuan, atau pengalaman itu merupakan suatu cara untuk memperoleh kebenaran pengetahuan. Oleh sebab itu pengalaman pribadi pun dapat digunakan sebagai upaya memperoleh pengetahuan.

Cara coba-coba ini dilakukan dengan menggunakan kemungkinan dalam memecahkan masalah, dan apabila kemungkinan tersebut tidak berhasil, dicoba kemungkinan yang lain. Apabila kemungkinan kedua ini gagal pula, maka dicoba kembali dengan kemungkinan ketiga, dan apabila kemungkinan ketiga gagal dicoba kemungkinan keempat dan seterusnya, sampai masalah tersebut dapat terpecahkan.

\section{Pelaksanaan aktifitas/olahraga.}

Berdasarkan hasil diskusi dengan 3 orang informan disimpulkan bahwa mereka sudah melakukan olahraga berupa pus up, site up, jalan-jalan, lari-lari kecil selama 30 menit - 40 menit yang dilakukan sebanyak $4-5$ kali dalam satu minggu. Dari 3 informan yang sudah melakukan olahraga, diperoleh kesimpulan bahwa mereka belum mengetahui cara mengukur tepat/tidaknya atau bilamana menghentikan olahraga yang mereka lakukan, mereka menghentikan olahraga apabila sudah capek/lelah, berkeringat, atau sudah mencapai 30 - 40 menit saja.

Hal ini sesuai dengan faktor yang mempengaruhi perilaku menurut Green diantaranya pengetahuan, sikap dan nilai suatu aktifitas/perilaku. Bila seseorang mengetahui manfaat dari suatu kegiatan/aktifitas, sikap dan nilai terhadap aktifitas tersebut baik atau positif, maka seseorang akan cenderung mau melakukan kegiatan/aktifitas tersebut, dalam hal ini aktifitas olah raga bagi penderita DM. Lebih dari setengah informan belum melakukan aktifitas olahraga karena kemungkinan kurang mengetahui manfaatnya, atau karena sikap informan negatif dan nilai manfaat olahraga tersebut tidak dirasakan leh penderita sebagai informan.

Sesuai dengan teori bahwa prinsip latihan jasmani bagi diabetes, persis sama dengan prinsip latihan jasmani secara umum, yaitu memenuhi beberapa hal:

a. Frekuensi jumlah olahraga perminggu sebaiknya dilakukan dengan teratur 3-5 kali seminggu

b. Intensitas ringan dan sedang (60-70\% maximum heartrate)

c. Durasi 30-60 menit

d. Jenis latihan jasmani endurans (aerobic) untuk meningkatkan kemampauan 
kardiorespirasi seperti jalan, jogging, berenang, dan bersepeda

Latihan jasmani bagi diabetes tipe I, sebaiknya dilakukan pada pagi hari. Untuk menentukan latihan, dapat digunakan maximum heart rate (MHR) yaitu: $220-$ umur. Setelah MHR didapatkan, dapat ditentukan target heart rate (THR). Sebagai contoh suatu latihan bagi seorang diabetes berumur 60 tahun didasarkan sebesar $75 \%$, maka $\mathrm{THR}=75 \% \times(220-60)=120$. Dengan demikian, diabetes dalam melakuakan latihan jasmani, sasaran denyut nadinya adalah 120/menit. Pada diabetes tipe II, latihan jasmani dapat memperbaiki kendali glukosa secara menyeluruh, terbukti dengan penurunan konsentrasi HbA1c, yang cukup menjadi pedoman untuk penurunan komplikasi diabetes dan kematian.

\section{Simpulan}

\section{Pengetahuan tentang Diabetes Melitus}

Informan telah mengetahui tentang DM karena mereka telah mengalami penyakit tersebut dan telah mendapat informasi melalui penyuluhan kesehatan pada waktu periksa dan berobat ke puskesmas

2. Pengetahuan tentang aktifitas/olahraga Informan ada yang sudah mengetahui dan melakukan olahraga yang tepat bagi penderita DM, tetapi masih ada informan yang tidak mengetahui dan tidak melakukan olahraga karena tidak tahu dan malas/lemes.

3. Pelaksanaan aktifitas/olahraga

Berdasarkan hasil diskusi dengan 3 orang informan bahwa mereka sudah melakukan olahraga berupa pus up, site up, jalan-jalan, lari-lari kecil selama 30 menit - 40 menit yang dilakukan sebanyak $4-5$ kali dalam satu minggu. namun mereka belum mengetahui cara mengukur tepat/tidaknya atau bilamana menghentikan olahraga yang mereka lakukan, mereka menghentikan olahraga apabila sudah capek/lelah, berkeringat, atau sudah mencapai $30-40$ menit saja.

\section{Daftar Pustaka}

Depkes RI, (2010), Pedoman

Penatalaksanaan Diabetes Mellitus di Puskesmas

Dinkes Kota Tangerang, (2013), Profil Kesehatan Kota Tangerang

Hasdianah, H R (2012), Mengenal Diabetes Melitus Pada Orang Dewasa Dan Anak-Anak Dengan Solusi Herbal, Yogyakarta, Nuha Medika.

Notoatmodjo, Soekidjo, (2007), Promosi Kesehatan, Rineka Cipta Jakarta

Sarwono Waspadji (2009), Penatalaksanaan Diabetes Melitus Terpadu, Jakarta: Rumah Sakit Cipto Mangunkusumo - FKUI

Setiyohadi Bambang, dkk (2007), Buku Ajar Ilmu Penyakit Dalam, Edisi IV, Jakarta, FKUI

Smeltzer C Suzanne (2002); Keperawatan Medikal Bedah Edisi 8 Vol 2, Jakarta, penerbit buku kedokteran EGC. 
www.google.com, Jumlah Penyakit

Diabetes Melitus Di Indonesia Pada

Tahun 2012

www.depkes.go.id (2012), Diabetes

Melitus dapat dicegah 